\title{
Variable Meiotic Behaviour among Plants of an Alloplasmic Line of Maize
}

\author{
L. Poggio ${ }^{1,2, *}$, M. Rosato ${ }^{1}$, L. B. Mazoti ${ }^{1}$ and C. A. Naranjo ${ }^{1}$ \\ ${ }^{1}$ Instituto Fitotécnico de Sta. Catalina (FCAF, UNLP)-Centro de Investigaciones Genéticas \\ (UNLP-CONICET-CIC), C.C. 4, 1836 Llavallol, Buenos Aires, Argentina \\ ${ }^{2}$ Departamento de Ciencias Biológicas, FCEN, UBA, Buenos Aires, Argentina
}

Accepted June 30, 1997

Mazoti (1978) described a transposon that induces instability in the Multiple Dominant line of maize (MDZ). According to this author, the cytoplasm of teosinte (Zea mays ssp. mexicana, Florida variety) could be an activator of this transposon inducing several morphological, physiological and cytological effects after several generations of backcrosses. In the MDZ, Mazoti and Velazquez (1962) had found a high percentage of pollen sterility, wide variation in the diameter of nucleoli, stickiness among meiotic chromosomes and, in cross section of anthers, very frequent intercellular contacts. In 1987, Mazoti reported that the pachytene knobs in the alloplasmic line have a larger size and a higher DNA content than in the Multiple Dominant line.

In the present work cytological analyses of the Multiple Dominant line of maize and its alloplasmic line with teosinte (MDE) were performed in order to investigate the influence of teosinte cytoplasm on the meiotic behaviour.

\section{Material and methods}

The material was maintained through inbreeding at the Instituto Fitotécnico de Santa Catalina (IFSC, UNLP). The Multiple Dominant line of maize (MDZ) (Dr. Randolph \#1877) was used as a recurrent male parent during 20 generations of backcrosses onto teosinte $(Z$. mays ssp. mexicana, Florida Variety) to obtain the alloplasmic line (MDE). These lines were obtained by L.B. Mazoti. Uniformity of ecological conditions was achieved by growing all the lines in the same plot. Moreover, to avoid particular environmental effects on meiotic behaviour or DNA content, the sampling of panicles for meiotic analysis and of roots for DNA measurement were made simultaneously for both alloplasmic and normal line (Control).

For meiotic studies immature male spikelets were fixed in $3: 1$ (ethanol:acetic acid) and pollen mother cells were squashed in $2 \%$ propionic haematoxilin and ferric citrate as mordant (Núñez 1968). The stainability of pollen was evaluated using Alexander (1967) technique. Comparisons of the mean of bivalents among lines were done through an ANOVA test and Scheffe method.

\section{Results and discussion}

The meiotic behaviour of the MDZ line was nearly regular showing univalents at a low frequency ( $\bar{X}_{\text {II }}$ from 9.22 \pm 0.09 to $9.56 \pm 0.07$; Table 1). The alloplasmic MDE line showed, in general, a higher mean of univalents $\left(\bar{X}_{I I}\right.$ from $7.94 \pm 0.17$ to $\left.9.12 \pm 0.13\right)$. It is important to point out that the MDZ line showed the same meiotic behaviour in all the flowers of the plant, while individuals of the alloplasmic MDE line showed meiotic abnormalities in the same plant.

\footnotetext{
* Corresponding author.
} 
Table 1. Meiotic behaviour in Metaphase I

\begin{tabular}{|c|c|c|c|c|c|c|c|c|c|c|c|c|}
\hline \multirow{2}{*}{ Lines } & \multirow{2}{*}{ Indiv. } & \multicolumn{8}{|c|}{ Meiotic configurations (number of cells) } & \multirow{2}{*}{$\overline{\mathrm{X}}_{\mathrm{II}} \pm \mathrm{S} . \mathrm{E}}$. & \multirow{2}{*}{$\bar{X}_{I} \pm S . E}$. & \multirow{2}{*}{$\begin{array}{l}\text { Total } \\
\text { cells }\end{array}$} \\
\hline & & $10 \mathrm{II}$ & $9 \mathrm{II}+2 \mathrm{I}$ & $8 \mathrm{II}+4 \mathrm{I}$ & $7 \mathrm{II}+6 \mathrm{I}$ & $6 \mathrm{II}+8 \mathrm{I}$ & $5 \mathrm{II}+10 \mathrm{I}$ & $2 I I+16 I$ & OII & & & \\
\hline \multirow[t]{2}{*}{$\mathrm{Z}$} & 7201 & 46 & 30 & 16 & & & & & & $9.32 \pm 0.08$ & $1.34 \pm 0.16$ & 92 \\
\hline & 7009 & 49 & 19 & 7 & & & & & & $9.56 \pm 0.07$ & $0.88 \pm 0.15$ & 75 \\
\hline \multirow[t]{4}{*}{$\mathrm{E}$} & 7202 & 22 & 21 & 29 & 8 & 17 & 5 & 1 & 1 & $7.94 \pm 0.17$ & $3.94 \pm 0.35$ & 104 \\
\hline & 7279 & 26 & 13 & 16 & & 1 & & & & $9.12 \pm 0.13$ & $1.75 \pm 0.25$ & 55 \\
\hline & 7280 & 13 & 10 & 8 & 7 & & & & & $8.76 \pm 0.18$ & $2.47 \pm 0.36$ & 38 \\
\hline & 7290 & 15 & 11 & 12 & 5 & & & & & $8.84 \pm 0.18$ & $2.32 \pm 0.32$ & 43 \\
\hline
\end{tabular}

Indeed, individuals belonging to the alloplasmic line presented variation in their meiotic behaviour in different parts of the panicle. In some secondary branches, the whole anthers have normal cells with $2 n=20$ chromosomes, while in other anthers of the same panicle cytological abnormalities were observed. These abnormalities consisted, among others, in drastic effects of cytomixis, the passage of chromatin from one cell into the cytoplasm of an adjoining cell through cytoplasmic channels. As a consequence, meiocytes could vary in their chromosome number from 7 to ca. 64 (Figs. 1E-H); other cells with normal chromosome complement showed some phenomena related to cytomixis such as chromosomes attached to the nuclear membrane (Fig. 1F). The frequency of flowers with cytomixis varied among individuals. It is interesting to point out that all the individuals of the MDE line presented evidences of cytomixis in their cells, even at low frequencies. The mean number of bivalents in cells with 20 chromosomes decreased very significantly in one individual of MDE (7202) $(F=20.737 ; p=$ 0.0001) when compared with other individual of the same line having the same complement. Another abnormal chromosome behaviour observed in some of the anthers was: nuclear fusion, pseudomultivalents (multivalents fromed by stickiness of the chromosomes), nucleolar bodies, asynapsis and persistent nucleolus (Figs. 1A-D). These cytological phenomena are in agreement with those described by Mazoti and Velazquez (1962) since the stickiness and intercellular contacts that these authors observed in sections of anthers could correspond with the pseudomultivalents and cytomixis found in the present paper. In Table 1 the mean number of bivalents and univalents are calculated only for normal cells (i.e. with 20 chromosomes). In the MDZ line cells with cytomixis were never observed.

In individuals of the MDE line the degree of pollen sterility varied from $48 \%$ to $0 \%$ in different anthers of the same plant, most probably as a consequence of the meiotic abnormalities observed in some of the flowers.

The causes of cytomixis are still not well known and subject to controversy. Some authors have considered cytomixis as a technical artifact, or caused by physiological and or environmental stress. In the genus Larrea (Hunziker et al. 1978) there exist evidences suggesting that the abnormalities leading to cytomixis are due to gene interaction in interspecific hybrids, probably as a consequence of gene differentiation during divergent evolution. This would not explain the differences in the meiotic behaviour of MDZ and MDE lines since they are different only in their cytoplasms.

The abnormalities were seen in all the plants of the alloplasmic line MDE and an explanation could be a nucleo-cytoplasmic interaction as a source of desequilibrium. Abnormalities such as cytomixis and nuclear fusion were never observed in another four alloplasmic lines without transposon but with the same teosinte cytoplasm (Poggio et al. 1991, 1994, in press). Another likely explanation is that the variable meiotic behaviour in the male spikelets observed in the alloplasmic line could be due to the instability produced by a transposon carried by the MDZ line, which becomes activated in the cytoplasm of $Z$. mays ssp. mexicana, as was postulated by Mazoti $(1978,1987)$. 

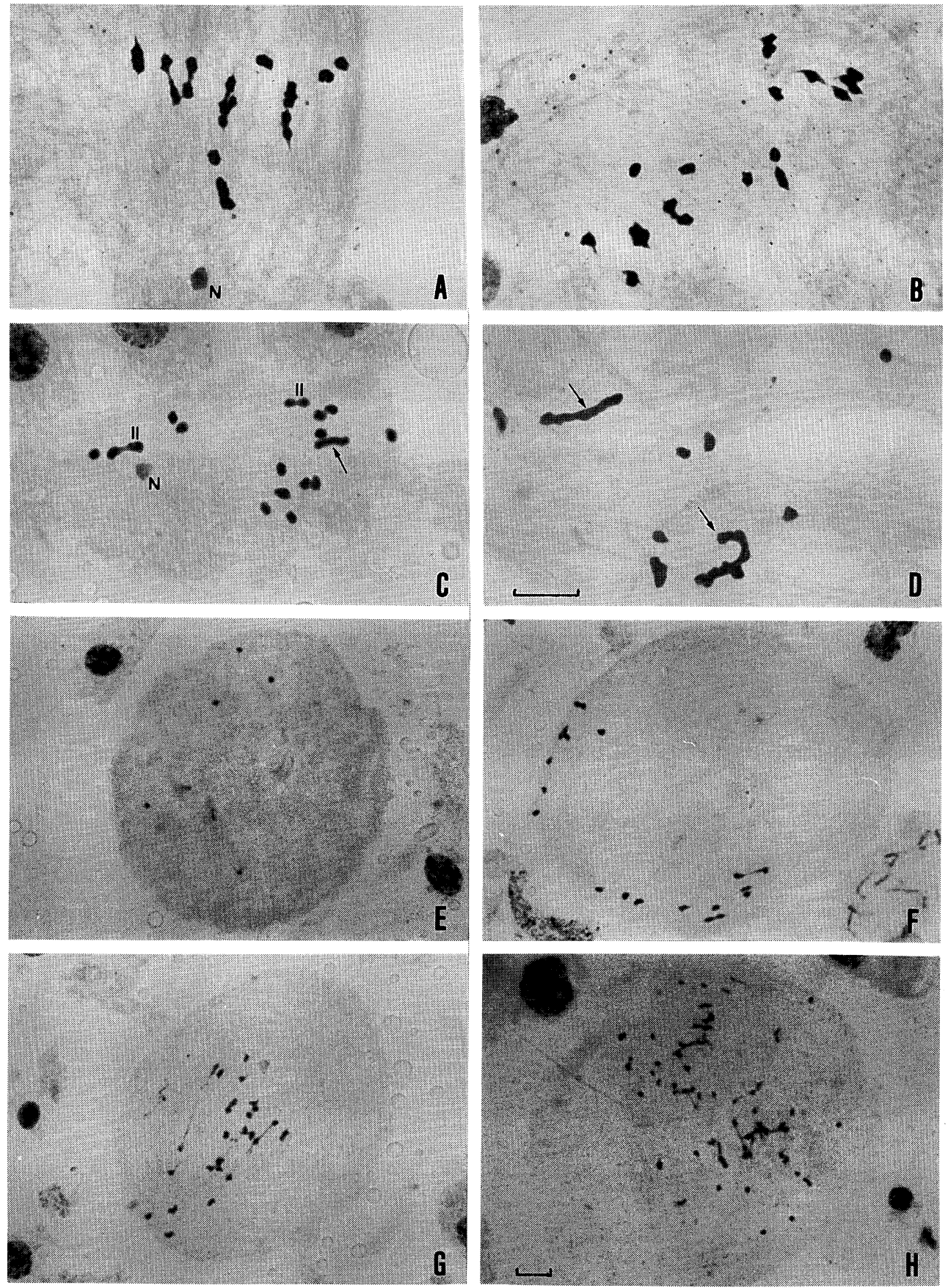

Fig. 1. Meiotic behaviour of the alloplasmic MDE line. $A=7 I I+6 I$ ( $N=$ persistent nucleolus $)$. $B=5 I I+10 I . \quad C=2 I I+16 I$ (arrow shown one pseudotrivalent) $(\mathrm{N}=$ persistent nucleolus). $\mathrm{D}=2$ pseudomultivalents. $\mathrm{E}=\mathrm{PMC}$ with 7 chromosomes. $\mathrm{F}=$ The chromosomes are attached at the nuclear membrane. $\mathrm{G}=\mathrm{PMC}$ with ca. 25 chromosomes. $\mathrm{H}=\mathbf{P M C}$ with ca. 64 chromosomes. The bars represent $10 \mu \mathrm{m} ; \mathrm{A}-\mathrm{D}$ and $\mathrm{E}-\mathrm{H}$ with the same enlargement.

The molecular explanation for the observed phenomena remains an open question. It is interesting to point out, however, that our data have some similarity with the molecular mechanism of speciation called "Genomic disease" postulated by Krieber and Rose (1986). 
These authors stated that dysgenesis due to a high level of transposition, with deleterious effects on the fitness of hybrids, could be relevant in the establishment of a reproductive barrier to gene exchange.

\section{Summary}

An alloplasmic line of maize (MDE) was produced by using the Multiple Dominant line (MDZ) as a recurrent male parent during 20 generations of backcrosses onto teosinte (Zea mays ssp. mexicana). The meiotic behaviour of both lines was carefully compared. The MDZ line has a transposon which can be activated by the cytoplasm of teosinte (Mazoti 1978). The analyses showed that all the individuals of MDZ had a regular meiosis, whereas the individuals of alloplasmic line presented several meiotic abnormalities in different parts of the panicle; the flowers showing cytomixis, fusion of nuclei, pseudomultivalents, asinapsis or persistent nucleolus at metaphase. The abnormal meiotic behaviour in alloplasmic line could be attributed to the action of the transposon carried by the MDZ line, which becomes activated in the cytoplasm of teosinte, such as it has been found by Mazoti (1.c.) for several morphological and cytological characteristics.

Key words : Alloplasmic line, Abnormal meiotic behaviour, Maize, Transposons, Cytomixis.

\section{Acknowledgements}

The authors are very grateful to Dr. Ovidio Núñez and Dra. Viviana Confalonieri for critical reading of the manuscript. This work has been supported by grants of the "Consejo Nacional de Investigaciones Cientificas y Técnicas (CONICET)", CIC (Buenos Aires) and the "Universidad de Buenos Aires", Argentina.

\section{References}

Alexander, M. P. 1967. Differential staining of aborted and non-aborted pollen. Stain Tech. 2(3): 117-137.

Krieber, M. and Rose, M. R. 1986. Molecular aspects of species barrier. Ann. Rev. Ecol. Syst. 17: 465-485.

Núñez, O. 1968. An acetic haematoxylin squash method for small chromosomes. Caryologia 21(2): 115-119.

Mazoti, L. B. 1978. Interacciones entre el gen C2-IE 7002 de Zea mays y un citoplasma (plasmón) diferenciado de Euchlaena mexicana. Rev. Facultad Agronomía, La Plata (3 ép.) LIV(2): 477-497.

- 1987. Variaciones en los knobs de Zea mays L, inducidas por un plasmón de Euchlaena mexicana Schrader. Mendeliana 8(1): 45-52.

- and Velazquez, R. S. 1962. Interacciones nucleocitoplasmáticas. Rev. Facultad Agronomía, La Plata (3a ép.) XXXVIII(1-2): 1-21.

Hunziker, J. H., Palacios, R. A., Valesi, A. G. and Poggio, L. 1978. Hybridization in Larrea (Zygophyllaceae): A morphological, cytogenetic and chemosystematic study. Bol. Acad. Nac. Cs. Córdoba (Argentina) 52: 281314.

Poggio, L., Tito, C., Mazoti, L. B. and Naranjo, C. A. 1991. Meiotic behavior and DNA content in two stable lines of Zea mays ssp mays with cytoplasm of Zea mays ssp. mexicana. Maize Genet. Coop. N.L. (USA) 64: 7576.

-, Naranjo, C. A., Rosato, M. and Mazoti, L. B. 1994. Cytological studies in alloplasmic lines of maize. Maize Genet. Coop. NL (USA) 68: 52.

-, Rosato, M. and Naranjo, C. A. Meiotic behavior and DNA content in alloplasmic lines of maize. Genome (in press). 